\title{
A Semi-Quantitative Model for the Burning Rate of Solid Materials
}

James G. Quintiere

Building and Fire Research Laboratory

Gaithersburg, Maryland 20899

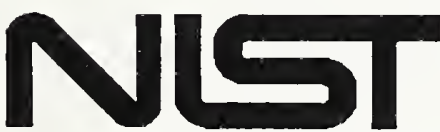

$-Q C \longrightarrow$ States Department of Commerce

100 ogy Administration

.056

1 Institute of Standards and Technology

C. 2 



\section{A Semi-Quantitative Model for the Burning Rate of Solid Materials}

James G. Quintiere

June 1992

Building and Fire Research Laboratory

National Institute of Standards and Technology

Gaithersburg, MD 20899

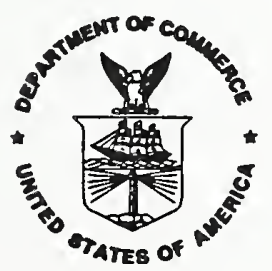

U.S. Department of Commerce

Barbara Hackman Franklin, Secretary

Technology Administration

Robert M. White, Under Secretary for Technology

National Institute of Standards and Technology

John W. Lyons, Director 



\section{Table of Contents}

Page

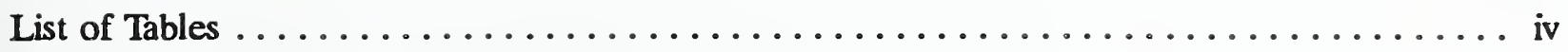

List of Figures $\ldots \ldots \ldots \ldots \ldots \ldots \ldots \ldots \ldots \ldots \ldots \ldots \ldots \ldots \ldots \ldots \ldots \ldots \ldots$

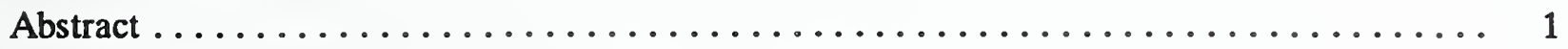

1. Introduction $\ldots \ldots \ldots \ldots \ldots \ldots \ldots \ldots \ldots \ldots \ldots \ldots \ldots \ldots \ldots \ldots \ldots \ldots \ldots \ldots \ldots \ldots$

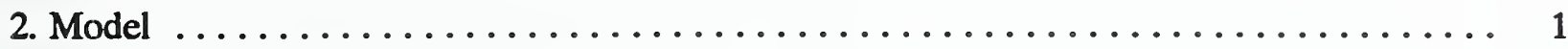

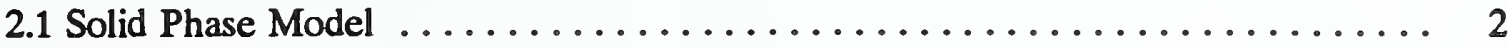

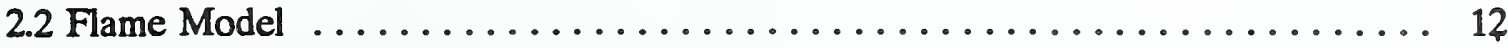

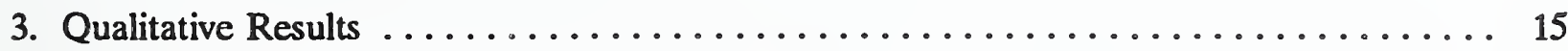

3.1 Examination of Experimental Results $\ldots \ldots \ldots \ldots \ldots \ldots \ldots \ldots \ldots \ldots$

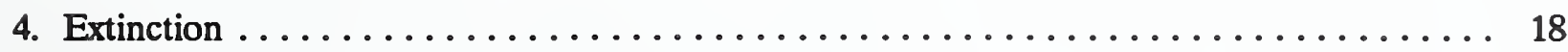

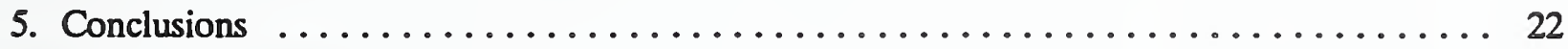

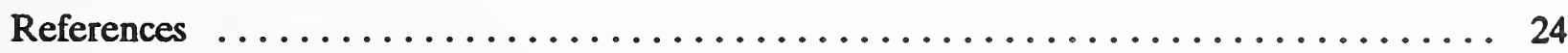

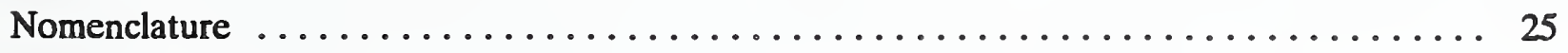




\section{List of Tables}

Page

Table 1. Heat of Gasification Values at Peak Burning Conditions $\ldots \ldots \ldots \ldots \ldots \ldots$ 


\section{List of Figures}

Page

Figure $1 . \quad$ Solid decomposition model $\ldots \ldots \ldots \ldots \ldots \ldots \ldots \ldots \ldots \ldots \ldots \ldots$

Figure 2a. Char layer process $\ldots \ldots \ldots \ldots \ldots \ldots \ldots \ldots \ldots \ldots \ldots \ldots \ldots \ldots \ldots \ldots \ldots \ldots \ldots \ldots . .29$

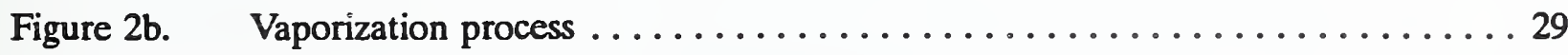

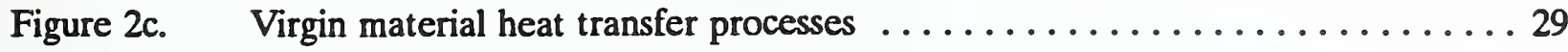

Figure 3. One dimensional diffusion flame system $\ldots \ldots \ldots \ldots \ldots \ldots \ldots \ldots \ldots . .30$

Figure 4. Qualitative description of burning rate for solids $\ldots \ldots \ldots \ldots \ldots \ldots \ldots$

Figure 5. Peak rates of mass loss versus irradiance for PMMA from

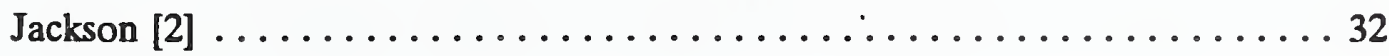

Figure 6. Peak mass loss rate for oak from Jackson $[2] \ldots \ldots \ldots \ldots \ldots \ldots$

Figure 7. Peak mass loss rate for particle board $[3,4,5] \ldots \ldots \ldots \ldots \ldots \ldots$

Figure 8. Energy and mass loss streams for diffusion flame $\ldots \ldots \ldots \ldots \ldots \ldots$

Figure 9. Burning rate of vertical PMMA slabs versus external radiant flux for various water application rates from Magee and Reitz[8] ....... 36 



\title{
A Semi-Quantitative Model for the Burning Rate of Solid Materials
}

\author{
James G. Quintiere
}

\section{Abstract}

An analytical model was developed to describe the processes involved in the burning and extinction of solid materials. Included are flame heat transfer, charring, transient conduction, and water application. The model qualitatively describes the burning rate of both charring and thermoplasticlike solids. It illustrates how the steady-state heat of gasification can be derived from peak burning rate test data taken as a function of irradiance. Experimental data are shown to support this derivation. The model, in conjunction with a critical flame temperature, is used to describe suppression and extinction by water.

Keywords: Burning rate, extinction, heat of gasification, fire models.

\section{Introduction}

The degradation of a solid in burning is a complex process. It involves flame heat transfer, evaporation or pyrolysis, possibly charring, and transient thermal effects. Although specific models have been developed, they are limited to classes of materials and do not apply in general. Test apparatuses, such as the Cone Calorimeter, provide a means for dynamically measuring the mass loss and energy release of solid materials, but the interpretation of the data is limited by the lack of a simple burning rate model. The purpose of this presentation is to describe a simple model that represents the significant effects in the burning of a solid, and to use that as a potential means for analyzing burning rate data. The intent is to lay out the governing equations so that some limited quantitative insight might be derived. The literature has not been reviewed for other charring models since depth of specific detail is not the objective here. Instead a simple but complete model for the principal factors of solid combustion are sought. At some later time, solutions to the governing equations will be conducted, and their relationship to data and other models in the literature will be examined. Ultimately we would like to have a model that is universally suited for describing the burn rate of any complex material in term of experimentally derived parameters.

\section{Model}


A one dimensional steady "stagnant-film" approach is used to describe the gas-phase combustion processes. The "stagnant-film" implies that the fluid boundary layer will be at rest, but its thickness will be determined from known heat transfer relationships. Terms for flame radiation and external radiation are included. It is assumed that variables respond quickly in the gas phase so that it is quasi-steady with respect to the solid phase. In the solid phase, charring, vaporization and transient conduction effects are considered. As vaporization of fuel occurs in the solid it instantaneously is transported to the surface with no resistance through the char layer. A global analysis will be used to describe the solid phase processes which will be linked to the gas-phase by the surface boundary condition. The stagnant film model is available in standard combustion texts (A.M. Kanury, Introduction to Combustion Phenomena, Gordon and Breach, 1977, pp 167-178), but is repeated here for completeness. First the solid phase analysis will be considered.

Figure 1 illustrates the model for decomposition in the solid. Vaporization is assumed to occur at a plane behind the char zone. Figure 2 decomposes this model into control volume regions, and displays the heat and mass transfer processes for each region. Measurements are based on the mass loss rate of the solid during burning, so we seek to represent the processes in terms of this quantity. Moreover, the heat of combustion or specie yields derived from measurements are given with respect to the measured mass loss rate. Thus, one may interpret these properties as effective values for the fuel gaseous mixture that leaves the solid. For example, if water vapor is driven off in addition to fuel pyrolyzate, the heat of combustion would represent that of this mixture.

In the following sections a detailed derivation of the solid and gas phase equations will be presented. For the most part, the control volume conservation laws for mass and energy will utilized. As a check and to offer another perspective, a differential formulation of the decomposing solid will be examined. The results will be shown consistent with the control volume formulation.

\subsection{Solid Phase Model}

The conservation of mass and energy will be applied to the regions depicted in Figures 2a-2c. These consist of the (a) the char, (b) the vaporization interface, and (c) the virgin solid. For mass conservation with respect to a control volume, the rate of change of mass within the control volume plus the net rate of mass flow out of the contol volume is equal to zero. The conservation of energy for a control volume states that the rate of change of internal energy within the contol volume plus the net rate of enthalpy out is equal to the net rate of heat addition. Work is neglected, except for flow work, and combustion energy can be treated as an effective heat addition. Constant properties will be assumed for each distinct media, i.e. char and virgin material; and the internal energy is referenced at the initial temperature.

\section{Conservation of mass for the entire solid}

The conservation of mass for the solid in Figure 1 is given by

$$
\frac{1}{A} \frac{d m}{d t}+\dot{m}^{\prime \prime}=0
$$


where $\frac{d m}{d t}$ is the mass rate of change of the solid,

$A$ is the surface area,

and $\mathrm{m}^{\prime \prime}$ is the mass flow rate of the gasified products per unit area.

Hence, $\mathrm{m}^{n}$ is the mass loss rate per unit surface area, or which is more commomly referred to as the burning rate (per unit area). Eq. (1) is not essential to the governing equations which follow, but is only presented to show the relationship between the rate of fuel gasses which flow out of the system and the rate of mass loss of the solid.

\section{Conservation of mass for the char}

By considering the conservation of mass for the char layer in Figure 2a, and assuming that the vaporized fuel instantaneously leaves the solid, it follows that

$$
\frac{d}{d t} \int_{0}^{\delta c} \rho_{c} d y_{s}=\dot{m}_{c}^{\prime \prime}
$$

where $\rho_{c}$ is the char density, and $\dot{m}_{c}{ }^{n}$ is the char mass flow rate per unit area from the vaporization plane. The accumulation of the fuel gases in the char matrix is taken to be negligible, so that the rate of gaseous fuel entering from the vaporization interface is equal to the rate of fuel gases which leave the solid to be be burned.

\section{Conservation of mass for the virgin solid}

Consequently, a conservation of mass on the virgin fuel element in Figure $2 c$ yields

$$
\frac{d}{d t} \int_{\delta_{c}}^{\delta_{c}+\delta_{\nu}} \rho d y_{s}+\rho v=0
$$

where $\rho$ is the density of the virgin solid, and where the control volume surface moves at the speed of the vaporization plane, $v=\frac{d \delta_{c}}{d t}=-\frac{d \delta_{v}}{d t}$. It is assumed that the thickness of the solid stays constant as decomposition occurs.

\section{Conservation of mass for the vaporization interface}


A mass balance at the vaporization plane together with Eq.(2), and assuming $\rho_{\mathrm{c}}$ is constant, gives

$$
\text { where } \begin{aligned}
\rho v & =\dot{m}^{\prime \prime}+\dot{m}_{c}^{\prime \prime}=\beta \dot{m}^{\prime \prime} \\
& =\rho /\left(\rho-\rho_{c}\right) .
\end{aligned}
$$

This equation states that the rate of mass from the virgin solid into the vaporization interface is equal to the mass flow rate of char and fuel gases leaving the vaporization interface.

The conservation of energy for each region in Figure 2 is now considered.

\section{Conservation of energy for the char}

For the char region (2a),

$$
\begin{gathered}
\frac{1}{A} \frac{d U_{c}}{d t}+\dot{m}^{\prime \prime} c_{g}\left(T_{s}-T_{v}\right)-\dot{m}_{c}^{\prime \prime} c_{c}\left(T_{v}-T_{\partial}\right)=\left(-k_{g} \frac{d T}{d y}\right)_{y=0}+\dot{q}_{f, r}^{\prime \prime}+\dot{q}_{e x, r}^{\prime \prime} \\
-\sigma T_{s}^{4}-\dot{q}_{v}^{\prime \prime}
\end{gathered}
$$

\begin{tabular}{|c|c|}
\hline $\mathrm{U}_{\mathrm{c}}$ & is the internal energy of the char layer, \\
\hline $\begin{array}{l}c_{g} \\
c_{c}\end{array}$ & $\begin{array}{l}\text { is the specific heat of the vaporized fuel gas, } \\
\text { is the char specific heat, }\end{array}$ \\
\hline$-\left(k_{8} \frac{d T}{d y}\right)_{y=0}$ & is the flame convective heat flux, \\
\hline $\begin{array}{l}q_{f, r}^{n} \\
q_{e x, r}^{n} \\
\sigma T_{s}^{4} \\
q_{v}^{n} v \\
T_{v}^{v} \\
T_{s} \\
T_{0}\end{array}$ & $\begin{array}{l}\text { is the flame radiative heat flux, } \\
\text { is the external radiative flux to the surface, } \\
\text { is the surface reradiative heat flux (assumed to be a blackbody), } \\
\text { is the heat flux to the plane of vaporization, } \\
\text { is the vaporization temperature, } \\
\text { is the surface temperature, } \\
\text { is the reference temperature. }\end{array}$ \\
\hline
\end{tabular}

where

Conservation of energy for the vaporization interface

The conservation of energy applied to the vaporization plane of Figure $2 b$ yields: 


$$
\text { ( } \rho v) \Delta H_{v}=\dot{q}_{v}^{\prime \prime}-\dot{q}_{k}^{\prime \prime}
$$

where $\Delta \mathrm{H}_{\mathrm{v}} \quad$ is the heat of vaporization (pyrolysis) for the solid at temperature $T_{v}$, $q_{k}^{n} \quad$ is the heat loss per unit area to the virgin solid.

The left side of Eq. (5) relates to the energy required to change the virgin solid to vapor and char, and can be taken as a definition of $\Delta \mathrm{H}_{\mathrm{r}}$

\section{Conservation of energy for the virgin solid}

An energy balance on the virgin solid gives

$$
\frac{1}{A} \frac{d U_{v}}{d t}+\rho v c\left(T_{v}-T_{0}\right)=\dot{q}_{k}^{\prime \prime}-\dot{q}_{b}^{\prime \prime}
$$

where $q_{b}^{n} \quad$ is the heat loss per unit area from the back of the solid, and $U_{v}$ is the internal energy of the virgin solid.

Since the density ( $\rho)$ and specific heat (c) of the virgin solid can be considered constants,

$$
U_{v}=\rho C A \int_{\delta_{c}}^{\delta_{v}+\delta_{c}}\left(T-T_{0}\right) d y_{s}
$$

Equations (2) - (7) constitute the governing equations for the solid phase. It is not entirely obvious what are the unknown variables, and what is the strategy of solving for them. For now it can be noted that by assuming appropriate profiles for the temperature, the heat fluxes can be expressed in terms of temperature by Fourier's Law. Also the variables involving the gas phase heat transfer need to be developed from the gas phase analysis to follow in the next section. Now a digression is introduced to illustrate another approach for presenting the solid phase equations, and to offer a check on the above analysis.

\section{Differential formulation}

Consider pure conductive heat transfer into the virgin solid with the space coordinate (x), fixed to the moving vaporization plane. This coordinate system is shown in Figure 1, and is introduced to 
avoid confusion with the $y_{s}$ coordinate system used above. If $x_{0}$ is the initial fixed reference system,

$$
x=x_{0}-\int_{0}^{8} v(\tau) d \tau
$$

where $\mathrm{v}$ is the velocity of the vaporization plane. The conduction equation in the fixed frame of reference is

$$
p c \frac{\partial T}{\partial t}=k \frac{\partial^{2} T}{\partial x_{0}^{2}}
$$

which transforms as

$$
\begin{aligned}
& \begin{aligned}
\left(\frac{\partial T}{\partial t}\right)_{x_{0}} & =\left(\frac{\partial T}{\partial t}\right)_{x}+\left(\frac{\partial T}{\partial x}\right)_{t} \frac{d x}{d t} \\
& =\left(\frac{\partial T}{\partial t}\right)_{x}-v\left(\frac{\partial T}{\partial x}\right)_{t}
\end{aligned} \\
& \text { and }\left(\frac{\partial^{2} T}{\partial x_{0}^{2}}\right)_{t}=\left(\frac{\partial^{2} T}{\partial x^{2}}\right)_{t}
\end{aligned}
$$

from Eq. (8). Hence in the moving frame of reference,

$$
\rho c\left[\left(\frac{\partial T}{\partial t}\right)_{x}-v\left(\frac{\partial T}{\partial x}\right)_{t}\right]=k\left(\frac{\partial^{2} T}{\partial x^{2}}\right)_{t}
$$

with the conditions: 


$$
\begin{aligned}
& x=0,-k \frac{\partial T}{\partial x}=\dot{q}_{k}^{\prime \prime} \\
& x=\delta_{v},-k \frac{\partial T}{\partial x}=\dot{q}_{b}^{\prime \prime}
\end{aligned}
$$

and $\quad t=0, T=T_{0}$, the initial temperature.

\section{Case 1. Non-charring steady burning}

Let us consider the ideal case of a non-charring material undergoing steady burning. If steady conditions prevail in the moving system, i.e., the temperature field is not changing in the virgin solid relative to the moving vaporization plane, and the back face conditions are negligible, i.e., a very thick solid, then Eq. (11) becomes

$$
-\rho c v \frac{d T}{d x}=k \frac{d^{2} T}{d x^{2}}
$$

From Eq. (3) and since $v=-\frac{d \delta_{v}}{d t}$

$$
-\dot{m}^{\prime \prime} c \frac{d T}{d x}=k \frac{d^{2} T}{d x^{2}}
$$

with conditions from Eq. (5) and (12)

$$
\begin{gathered}
x=0,-k \frac{\partial T}{\partial x}=\dot{q}_{v}^{\prime \prime}-\dot{m}^{\prime \prime} \Delta H_{v} \\
x=0, T=T_{v} \\
x \rightarrow \infty, T=T_{0}
\end{gathered}
$$

Using Eqns (15b) and (15c) 


$$
\frac{T-T_{0}}{T_{v}-T_{0}}=e^{-\frac{c k n}{k} x}
$$

and from Eq. (15a)

$$
\dot{m}^{\prime \prime}=\frac{\dot{q}_{v}^{\prime \prime}}{\Delta H_{v}+c\left(T_{v}-T_{\partial}\right)}
$$

The denominator of Eq. (17) is commonly referred to as the steady state heat of gasification $\left(\mathrm{L}_{\mathrm{g}}\right)$.

$$
L_{g}=\Delta H_{v}+c\left(T_{v}-T_{0}\right)
$$

\section{Case 2. Transient charring}

In general, other terms which will be considered below will affect the mass loss rate, $\dot{m}^{\prime \prime}$. If the process is not steady, we can consider Eq. (11) by integrating each item over $\delta_{\mathrm{v}}$ :

$$
\begin{aligned}
\int_{0}^{\delta_{v}} k \frac{\partial^{2} T}{\partial x^{2}} d x & =\left.k \frac{\partial T}{\partial x}\right|_{x=0} ^{x=\delta_{v}}=\left(-\dot{q}_{b}^{\prime \prime}\right)-\left(-\dot{q}_{k}^{\prime \prime}\right) \\
\rho c \int_{0}^{\delta_{v}}\left(-v \frac{\partial T}{\partial x}\right) d x & =-\left.c \dot{m}^{\prime \prime} T\right|_{x=0} ^{x=\delta_{v}}=-c \dot{m}^{\prime \prime}\left(T_{b}-T_{v}\right) \\
\rho c \int_{0}^{\delta_{v}}\left(\frac{\partial T}{\partial t}\right) d x & =\rho c \frac{d}{d t} \int_{0}^{\delta_{v}} T d x-\rho c T\left(\delta_{v}, t\right) \frac{d \delta_{v}}{d t} \\
& =\rho c \frac{d}{d t} \int_{0}^{\delta_{v}} T d x+c \dot{m}^{\prime \prime} T_{b} \\
& =\rho c \frac{d}{d t} \int_{0}^{\delta_{v}}\left(T-T_{0}\right) d x+c \dot{m}^{\prime \prime}\left(T_{b}-T_{0}\right)
\end{aligned}
$$


Also for the charring case since at the vaporization plane $v=-\frac{d \delta_{y}}{d t}=\frac{d \delta_{c}}{d t}$, and from Eq. (3b) it follows that $\mathrm{m}^{n}$ should be replaced by $\beta \mathrm{m}^{n}$ in the above.

Substituting in the integrated form of Eq. (11) gives

$$
\begin{aligned}
\rho c \frac{d}{d t} \int_{0}^{\delta_{v}}\left(T-T_{0}\right) d x+ & \beta \dot{m}^{\prime \prime} c\left(T_{b}-T_{0}\right)-\beta \dot{m}^{\prime \prime} c\left(T_{b}-T_{v}\right) \\
& =\dot{q}_{k}^{\prime \prime}-\dot{q}_{b}^{\prime \prime}
\end{aligned}
$$

which is identical to Eq. (6). This demonstrates that the conservation of energy for the virgin solid is consistent with this differential formulation.

\section{Solution strategy}

In review, six independent equations have been presented consisting of conservation of mass and energy for the char, vaporizing interface, and virgin solid. These can be combined so that only two energy equations (4 and 6) are considered with the unknown variables: char depth, surface temperature, and a variable to be introduced which represents the thermal effects in the virgin solid. The thickness of the virgin solid and the mass burning rate can be related to the char depth, and the heat fluxes can be related to temperature profiles to be assumed in terms of the thicknesses of the char and virgin solid. A third equation will be found from the gas phase flame analysis which will give a relationship for the burning rate. The flame convective and radiative heat fluxes will be expressed in terms of the current variables from the gas phase flame analysis. Below, this section will be concluded with a derivation of the convective flame heat transfer based on the above conservation equations which will serve as a boundary condition to the gas phase analysis developed in the next section. This couples the solid and gas phase analyses.

From Eqns. (5) and (6)

$$
\begin{aligned}
& \rho c \frac{d}{d t} \int_{0}^{\delta_{v}}\left(T-T_{0}\right) d x+\beta \dot{m}^{\prime \prime} c\left(T_{v}-T_{0}\right)=\dot{q}_{v}^{\prime \prime}-\beta \dot{m}^{\prime \prime} \Delta H_{v}-\dot{q}_{b}^{\prime \prime} \\
& \text { or } \\
& \beta \dot{m}^{\prime \prime} L_{g}=\dot{q}_{v}^{\prime \prime}-\dot{q}_{b}^{\prime \prime}-\rho c \frac{d}{d t} \int_{0}^{\delta_{v}}\left(T-T_{0}\right) d x .
\end{aligned}
$$


This is a departure from the steady state results given by Eq. (17). It applies to the non-charring case if $q_{v}{ }^{\prime \prime}$ is regarded as the net surface heat flux, and $\beta=1$.

The more general charring case is considered by eliminating $\mathrm{q}_{\mathrm{v}}{ }^{\text {}}$ from Eq. (19) by using Eq. (4). Furthermore, the internal energy of the char is represented as follows:

$\frac{U_{c}}{A}=\int_{0}^{\delta_{c}} P_{c} u_{c} d y_{s}$ where $y_{s}$ is measured from the charring surface. The internal energy per unit mass, $u_{c}$, is represented as $c_{c}\left(T-T_{o}\right)$ where $c_{c}$ is the char specific heat. By Eq. (2) it follows that

$$
\frac{1}{A} \frac{d U_{c}}{d t}=p_{c} c_{c} \frac{d}{d t} \int_{0}^{B_{c}}\left(T-T_{0}\right) d y_{s}
$$

Combining all of the energy equations for the solid, or from Eqns. (4), (19) and (20)

$$
\begin{aligned}
& \beta \dot{m}^{\prime \prime} L_{g}=\left(-k_{g} \frac{d T}{d y}\right)_{y=0}+\dot{q}_{f_{p}}^{\prime \prime}+\dot{q}_{c x, r}^{\prime \prime} \\
&-\sigma T_{s}^{4}-\rho_{c} c_{c} \frac{d}{d t} \int_{0}^{\delta_{c}}\left(T-T_{0}\right) d y_{s}-\dot{m}^{\prime \prime} c_{g}\left(T_{s}-T_{v}\right) \\
&-\dot{q}_{b}^{\prime \prime}-\rho c \frac{d}{d t} \int_{\delta_{c}}^{\delta_{v}+\delta_{c}}\left(T-T_{0}\right) d y_{s} \\
&+\rho_{c} \beta \dot{m}^{\prime \prime} c_{c}\left(T_{v}-T_{o}\right)
\end{aligned}
$$


Alternatively,

$$
\begin{aligned}
& \beta \dot{m}^{\prime \prime} L_{g}=\left(-k_{g} \frac{d T_{g}}{d y}\right)_{y=0}+\dot{q}_{f, r}^{\prime \prime}+\quad \dot{q}_{c \infty, r}^{\prime \prime}-\quad \sigma T_{v}^{4} \\
& \text { convective flame external reradiation } \\
& \text { heat transfer radiation radiation (noncharring) } \\
& -\sigma\left(T_{s}^{4}-T_{v}^{4}\right)-\rho_{c} c_{c} \frac{d}{d t} \int_{0}^{\delta_{c}}\left(T-T_{0}\right) d y_{s} \\
& \text { surface reradiation energy storage } \\
& \text { due to charring due to charring } \\
& -\dot{m}^{\prime \prime} c_{\delta}\left(T_{s}-T_{v}\right)+\delta_{c} \beta \dot{m}^{\prime \prime} c_{d}\left(T_{v}-T_{\alpha} / \rho-\dot{q}_{b}^{\prime \prime}\right. \\
& \text { energy flow through char back face heat loss } \\
& -\rho c \frac{d}{d t} \int_{\delta_{c}}^{\delta_{v}}\left(T-T_{0}\right) d y_{s}
\end{aligned}
$$

virgin solid energy storage

(The above labels are qualitative descriptions of the terms.) 
Equation (21b) gives the thermal boundary condition for the gas phase analysis, i.e.,

$$
\begin{gathered}
-k_{g}\left(\frac{d T_{g}}{d y}\right)=\beta \dot{m}^{\prime \prime} \mathscr{L} \\
\text { where } \mathscr{L} \equiv L_{g}+\frac{\rho c \frac{d}{d t} \int_{\delta_{c}}^{\delta_{v}+\delta_{c}}\left(T-T_{0}\right) d y_{s}+\dot{q}_{b}^{\prime \prime}+\rho_{c} c_{c} \frac{d}{d t} \int_{0}^{\delta_{c}}\left(T-T_{0}\right) d y_{s}}{\beta \dot{m}^{\prime \prime}} \\
+\frac{\dot{m}^{\prime \prime} c_{g}\left(T_{s}-T_{v}\right)-\rho_{c} \beta \dot{m}^{\prime \prime} c_{c}\left(T_{v}-T_{o}\right) / \rho+\sigma T_{s}^{A}}{\beta \dot{m}^{\prime \prime}} \\
-\frac{\dot{q}_{f, r}^{\prime \prime}+\dot{q}_{e x t, r}^{\prime \prime}}{\beta \dot{m}^{\prime \prime}}
\end{gathered}
$$

The form in Eq. (22) constitutes a boundary condition for the gas phase problem to follow.

\subsection{Flame Model}

The gas-phase one dimensional diffusion flame is solved by conventional means (e.g., Kanury [7]). The conservation of mass, energy and species are considered for a vaporizing solid. A stagnant film of thickness $\delta_{\mathrm{g}}$ represents the boundary layer thickness or domain of the combustion region. Only one dimensional diffusive effects are considered with all of the convective effects due to transverse fluid motion accounted for by deriving $\delta_{\mathrm{g}}$ from known convective heat transfer results. The steady equations are listed below and relate to the diagram in Figure 3: 


\section{Conservation of mass}

$$
\dot{m}^{\prime \prime}=\text { constant for all } y,
$$

\section{Conservation of energy}

$$
\dot{m}^{\prime \prime} c_{g} \frac{d T_{g}}{d y}=k_{g} \frac{d^{2} T_{g}}{d y^{2}}-\dot{m}_{f}^{\prime \prime \prime} \Delta H_{c}\left(1-\chi_{r}\right)
$$

\section{Conservation of oxygen}

$$
\dot{m}^{\prime \prime} \frac{d Y_{a x}}{d y}=\rho_{8} D \frac{d^{2} Y_{a x}}{d y^{2}}+\dot{m}_{a x}^{\prime \prime \prime}
$$

All of the fluid properties are assumed constant. D is the diffusion coefficient and the Lewis number, $\mathrm{k}_{\mathrm{g}} / \rho_{\mathrm{g}} \mathrm{c}_{\mathrm{g}} \mathrm{D}$ is assumed equal to one. Stoichiometry gives

$$
\dot{m}_{a x}^{\prime \prime \prime}=r \dot{m}_{f}^{\prime \prime \prime}
$$

where $r$ is the stoichiometric oxygen to fuel mass ratio, $\dot{m}_{f}^{\prime \prime \prime}$ and $\dot{m}_{o x}^{\prime \prime \prime}$ are the respective rates of generation per unit volume for fuel and oxygen.

Boundary conditions 
The boundary conditions are given as

$$
\begin{aligned}
& y=\delta_{g}, T=T_{\infty} \\
& \text { and } Y_{a x}=Y_{o x, \infty} \\
& y=0, T=T_{s} \\
& \frac{d Y_{a x}}{d y}=0 \\
& \text { and }-k_{g} \frac{d T_{g}}{d y}=\dot{m}^{\prime \prime} \beta \subseteq \mathscr{E} E q \text {. (22). }
\end{aligned}
$$

\section{Burning rate solution}

By introducing a new variable,

$$
b=T+\frac{\Delta H_{c}\left(1-\chi_{r}\right)}{r c_{g}} Y_{a x}
$$

based on adding Eqns. (24) and (25) in order to eliminate the chemical source terms it can be shown that

$$
\dot{m}^{\prime \prime}=\frac{h}{c_{g}} \ln (1+B)
$$

where

$$
B=\frac{Y_{o x, \infty}\left(1-\chi_{r}\right) \Delta H_{d} / r+c_{g}\left(T_{\infty}-T_{s}\right)}{\beta \mathscr{L}}
$$

and $\frac{k_{g}}{\delta_{g}}$ has been replaced by h, a convective heat transfer coefficient. 


\section{Flame heat flux}

By introducing

$$
\xi=\frac{\dot{m}^{\prime \prime} c_{8}}{h}
$$

it can be shown from Eq. (22) that at $y=0$

$$
-k_{8} \frac{d T_{8}}{d y}=\left(\frac{\xi}{e^{\xi}-1}\right) \frac{h}{c_{g}}\left[Y_{o x, \infty} \frac{\Delta H_{c}\left(1-\chi_{r}\right)}{r}+c_{g}\left(T_{\infty}-T_{s}\right)\right]
$$

which is the convective heat flux to the surface. The quantity $\xi /\left(e^{\xi}-1\right)$ is called the "blocking factor" which effectively reduces $h$ from its pure heat transfer value as the mass transfer, $\mathrm{m}^{n}$, increases.

\section{Closure on solution strategy}

Eqns. (29) and (32) provide the two needed additional relationships that allow a solution to the complete set of equations. A solution of the transient equations will not be attempted in this presentation, but instead some qualitative observations will be made, and an extinction criterion will be examined. In a future investigation it is intended that these equations will be solved, and the extinction criterion will be used to obtain a full simulation of the burning rate for a typical solid.

\section{Qualitative Results}

Although it is possible to pursue approximate solutions by assuming temperature profiles for the solid, this will not be done. Instead, qualitative analyses will be explored to describe the general burning behavior of solids. Initially, as the solid reaches its vaporization temperature $T_{v}$ it behaves like a thermoplastic or non-charring material before a significant char layer is developed. To simplify the interpretation it is useful to initially consider the blocking factor and the flame radiant heat flux to be constants. The former will decrease with $\dot{m}^{\prime \prime}$ while $\dot{q}_{f, r}^{\prime \prime}$ is likely to increase with $\dot{m}^{\prime \prime}$ due to an increase in the flame thickness. Both of these effects can be used to temper the descriptions below.

Figure 4 depicts the behavior of the burning rate over time as vaporization ensues after time zero. For a non-charring material, the surface approximately remains at $T_{v}$ and only the energy storage term in the material affects the burn rate provided the solid is thick so no significant back-face heat loss occurs. As time increases, the energy storage term approaches zero (see Eqs (17) and (19)) as 
a steady-state is sought. However, once thermal effects are felt at the back-face, the burn rate is disturbed. For a back-face substrate with a lower conductivity than the burning solid, an increase in the burn rate will occur until burn-out of the solid. The opposite effect will result for a higher conductivity substrate.

If charring occurs the behavior is more complex, but describable by Eq. (21b). Initially, the burning begins like the non-charring case. But as the char layer increases, $T_{\mathrm{s}}$ increases and the charring terms in Eq. (21b) all increase to reduce the burning rate. This is shown in Figure 4, again with a corresponding back-face heat loss effect. At the maximum for the charring curve and for the peak of the non-charring curve before back-face effects occur, it can be argued that the following terms are small:

$$
\begin{gathered}
\rho c \frac{d}{d t} \int_{\delta_{c}}^{\delta_{v}+\delta_{c}}\left(T-T_{0}\right) d y_{s} \approx 0 \text { (since we assume the peak is near steady-state) } \\
0\left(T_{s}^{4}-T_{v}^{4}\right) \approx 0 \text { (since } T_{s} \approx T_{v} \text { before charring effects may increase the surface } \\
\text { significantly above its ignition temperature) }
\end{gathered}
$$

Admittedly, the above arguments are not subtantiated, and must require analysis of at least the solutions for the burning rate problem. However they are accepted as approximations for now. Therefore, these peak burning rate conditions, Eq. (21b) can be approximated as 


$$
\dot{m}_{\max }^{\prime \prime} \beta L_{g} \approx\left(\frac{\xi}{e^{\xi}-1}\right) \frac{h}{c_{g}}\left[Y_{o x_{s o}} \Delta H_{c}\left(1-\chi_{r}\right) / r+c_{g}\left(T_{\infty}-T_{v}\right]+\dot{q}_{f_{r},}^{\prime \prime}+\dot{q}_{e x, r}^{\prime \prime}-\sigma T_{v}^{4}\right.
$$

where $\beta \mathrm{L}_{\mathrm{g}}$ can be regarded as the steady state heat of gasification for a charring materials in general.

If in a test apparatus the convective and radiative flame heat fluxes do not vary greatly over a range of peak mass loss rates, then the variation of $m_{\max }^{n}$ with $q_{e x t, r}^{n}$ will be linear. The slope is $1 / \beta L_{g}$ and provides an approximate method for determining $\beta L_{g}$. Moreover, if the flame heat fluxes could be determined, Eq. (33) would provide a means for estimating the peak burn rate per unit area for, in principle, all fire conditions. Thus, given $\beta \mathrm{L}_{\mathrm{g}}$ for the material, and a knowledge of the fire heat fluxes, the burning rate can be estimated. This procedure provides a framework for utilizing small scale data such as that developed from the Cone Calorimeter and similar devices.

\subsection{Examination of Experimental Results}

It is generally found that small scale test data for the mass or energy release rate of materials is an approximate linear function of irradiance $q_{\text {ext, }, r}^{n}$ Tewarson [1] has shown this to be the case, and has utilized heating in nitrogen to derive $\mathrm{L}_{\mathrm{g}}$ from Eq. (33). In the case of nitrogen, the flame heat transfer terms are non-existent. Jackson [2] performed similar experiments in a nitrogen atmosphere and investigated effects over time. He defined a bulk heat of gasification of the solid as the total net heat added divided by the instantaneous mass loss rate. In terms of Eq. (21), this would correspond in a nitrogen (non-flaming) system as

$$
\begin{gathered}
\left(L_{g}\right)_{b u l k}=\beta L_{g}+\rho c \frac{d}{d t} \int_{\delta_{c}}^{\delta_{v}+\delta_{c}}\left(T-T_{\partial}\right) d y_{s} / \dot{m}^{\prime \prime} \\
+\rho_{c} c_{c} \frac{d}{d t} \int_{0}^{\delta_{c}}\left(T-T_{\partial}\right) d y_{s} / \dot{m}^{\prime \prime}+c_{g}\left(T_{s}-T_{v}\right) \\
-\rho_{c} \beta c_{c}\left(T_{v}-T_{\partial}\right) / \rho
\end{gathered}
$$

Based on our previous discussion, the bulk heat of gasification for a non-charring material would asymptotically approach $\mathrm{L}_{\mathrm{g}}$, the steady value as the energy storage term goes to zero. Jackson, 
indeed, finds this to occur for PMMA measurements from which yield $\left(\mathrm{L}_{\mathrm{g}}\right)_{\text {bulk }}$ as a function of time, but the asymptote depended on the irradiance level. This dependence could have been a result of inaccuracies in his estimation of the back-face heat loss terms as suggested by the fact that the effect on $\mathrm{L}_{\mathrm{g}}$ was diminished as the irradiance increased. Figure 5 shows Jackson's results for PMMA in terms of peak mass loss rate plotted for various irradiation levels. The slope of those data yield $\mathrm{L}_{\mathrm{g}}$ $=1.89 \mathrm{~kJ} / \mathrm{g}$ as suggested by using Eq. (33). This is compared to a time asymptotic value at $40 \mathrm{~kW} / \mathrm{m}^{2}$ irradiance of $1.65 \mathrm{~kJ} / \mathrm{g}$. This compares to a steady-state value by Tewarson of $1.63 \mathrm{~kJ} / \mathrm{g}$ [1]. Figure 6 shows peak values of $\mathrm{m}^{n}$ plotted for oak as taken by Jackson in nitrogen. From the slope of these data, $\mathrm{L}_{\mathrm{g}}$ (or more precisely $\beta \mathrm{L}_{\mathrm{g}}$ ) for oak is determined as $4.0 \mathrm{~kJ} / \mathrm{g}$.

An example of data taken under flaming conditions is presented in Figure 7 for particle board. These samples were tested vertically at a nominal size of $0.3 \mathrm{~m}$ high. The data come from Walton and Twilley [3] for irradiances of 25,50 and $74 \mathrm{~kW} / \mathrm{m}^{2}$, and for 0 irradiance as determined by Kulkarni [4]. Also shown are data from Tsantiadis and Ostman [5] for a particle board material that may not necessarily be identical to that of the other studies. Whether the absolute peak or an average peak value for $\mathrm{m}^{n}$ is used, the results for $\mathrm{L}_{\mathrm{g}}$ range from 4.4 to $4.7 \mathrm{~kJ} / \mathrm{g}$. If one applies this technique to a wide range of data for materials used in a series of room fire tests performed in Sweden [5], the $\mathrm{L}_{\mathrm{g}}$ values can be determined and are given in Table 1. It is not possible to develop an explanation for the trends of these data, and to explain them in terms of their material composition. The result for $\mathrm{L}_{\mathrm{g}}$ can simply be regarded as empirical which allow the prediction of the change in mass loss rate with the change in surface heat flux. However, Eq. (33) gives a physical interpretation to $\mathrm{L}_{\mathrm{g}}$ making it the steady-state heat of gasification appropriate to burning a liquid-like fuel. Although this mechanism of pyrolysis will be very different from the evaporation of a liquid, the model being used appears to give a first-order representation of peak mass loss with heat flux in a range of conditions appropriate to common building fires.

\section{Extinction}

To close this simplified view of burning, extinction is considered in terms of a critical flame temperature criterion. It is empirically established that for both pre-mixed flames at the lower flammable limit and for diffusion flames at extinction, a minimum flame temperature corresponds to these phenomena. Typically this critical temperature is roughly $1600 \mathrm{~K}$ for many $\mathrm{C}-\mathrm{H}-\mathrm{O}$ fuels burning in air (e.q. Williams reports measured values at extinction of $1500 \pm 50 \mathrm{~K}[6]$ ). Based on this concept, it can be investigated how the flame temperature in the stagnant film flame model can be reduced through heat losses. Equation (21) can be used as a boundary condition to establish the net heat losses from the flame at the fuel surface. One approach is to return to the stagnant film flame model and solve for the temperature at the flame sheet.

\section{Flame temperature}

Because we have included more heat transfer processes than would be consistent with the pure convective stagnant film model we must consider the relevance of these fluxes on flame temperature. A control volume approach is taken as shown in Figure 3. The heat and mass transfer processes that directly affect the flame temperature are illustrated in Figure 8. The radiative loss from the flame is accounted for by an effective decrease to the heat of combustion -- yielding less chemical energy available to produce the flame temperature. Therefore, the only heat loss from the flame (control 
volume) involves the convective heat flux to the fuel surface -- this constitutes $\dot{q}_{\text {net }}^{n}$ shown in Figure 8. The other heat fluxes $q_{\text {ext,r }}^{n}$, to the surface, and $\sigma \mathrm{T}_{s}^{4}$, from the surface are considered not to interact with the flame system.

By conservation of mass under steady state conditions, the mass flux of combustion products flowing out of the system is equal to the mass flux of fuel gases and the mass flux of air flowing in to the system:

$$
\dot{m}_{p}^{\prime \prime}=\dot{m}^{\prime \prime}+\dot{m}_{a}^{\prime \prime} \text {, }
$$

and by conservation of energy and Eq. (22),

$$
\dot{m}_{p}^{\prime \prime} c_{g}\left(T_{f}-T_{\partial}\right)-\dot{m}^{\prime \prime} c_{g}\left(T_{s}-T_{\omega}\right)=\dot{m}^{\prime \prime} \Delta H_{c}\left(1-\mathrm{X}_{r}\right)-\dot{m}^{\prime \prime} \beta \mathscr{Q}^{\prime}
$$

where $\mathscr{L}^{\prime}=\mathscr{L}+\frac{\dot{q}_{f, r}^{\prime \prime}}{\beta \dot{m}^{\prime \prime}}$ by Eq. (22) because the flame heat flux, $\dot{q}_{\mathrm{f}, \mathrm{r}, \mathrm{n}}^{\mathrm{n}}$, in this analysis since all the flame radiative loss is accounted for by $\chi_{r}$

Also by stoichiometry:

$$
\begin{aligned}
& \quad \dot{m}_{a}^{\prime \prime}=\dot{m}^{\prime \prime} \frac{r}{Y_{o x, \infty}} \\
& \text { and } \\
& \dot{m}_{p}^{\prime \prime}=\dot{m}^{\prime \prime}\left(1+\frac{r}{Y_{o x, \infty}}\right) .
\end{aligned}
$$

Then solving for $T_{f}$ yields

$$
c_{g}\left(T_{f}-T_{s}\right)=\frac{\left[\Delta H_{c}\left(1-X_{r}\right)-\beta \mathscr{L}^{\prime}\right] Y_{o x_{, \infty}} / r+c_{g}\left(T_{-s}-T_{s}\right)}{1+Y_{o x_{0} \infty} / r}
$$

which can be found in Kanury [7] for the case of pure convection: $\mathscr{L}^{\prime}=\mathrm{L}_{\mathrm{g}}, \mathrm{T}_{\mathrm{s}}=\mathrm{T}_{\mathrm{v}}$ and $\mathrm{X}_{\mathrm{T}}=0$. The quantities that reduce $T_{f}$ and drive the flame towards extinction are readily seen: 


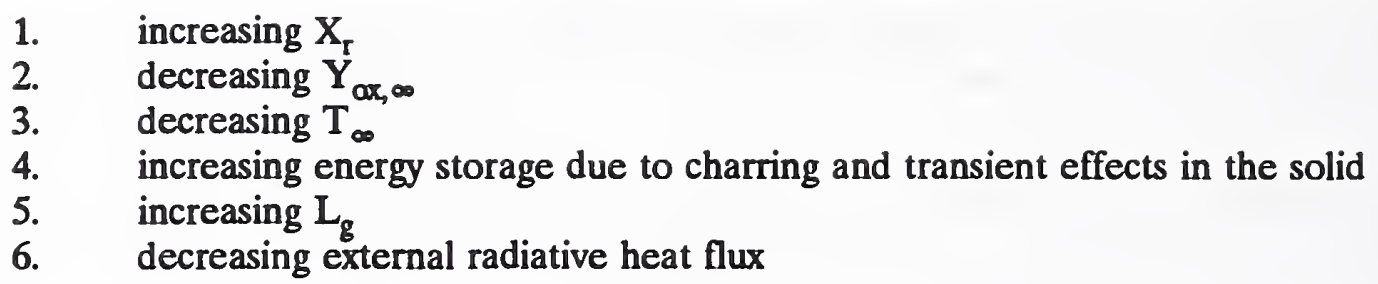

Extinction by the evaporation of water can also be accounted for by adding $\dot{m}_{w}^{\prime \prime} L_{w} / \dot{m}^{n}$ to the right side of Eq. (22) if $\mathrm{m}_{\mathrm{w}}$ is the mass evaporation rate of water per area of the solid surface and $\mathrm{L}_{\mathrm{w}}$ is the heat of gasification of the water $(2.6 \mathrm{~kJ} / \mathrm{g})$.

As an example of how to apply the temperature criterion consider some simple cases.

\section{Example 1. Steady burning of PMMA}

Take the fuel to be PMMA and ignore all transient and radiative effects. We might expect flame radiative effects to be small near extinction, but not transient and reradiation effects. Hence our result will be illustrative, but approximate. The following properties are used:

$$
\begin{array}{ll}
\mathrm{c}_{g} & =1 \mathrm{~J} / \mathrm{gK} \\
\mathrm{T}_{\infty} & =20^{\circ} \mathrm{C} \\
\mathrm{T}_{\mathrm{v}} & =377^{\circ} \mathrm{C} \\
\Delta \mathrm{H}_{\mathrm{c}} & =25.2 \mathrm{~kJ} / \mathrm{g} \\
\mathrm{L}_{\mathrm{g}} & =1.63 \mathrm{~kJ} / \mathrm{g} \\
\mathrm{r} & =2 \mathrm{~g} \text { oxygen } / \mathrm{g} \text { PMMA }
\end{array}
$$

Using $T_{f}=1600 \mathrm{~K}$, we can estimate the $Y_{a x}$ os to cause extinction of this PMMA flame. Substituting into Eq. (38) yields:

$$
\begin{gathered}
\left(10^{-3}\right)(1600-650)=\frac{(25.2-1.63) Y_{o x, \omega} / 2+\left(10^{-3}\right)(293-650)}{1+Y_{o x, \infty} / 2} \\
Y_{o x, \infty}=\frac{1.376}{4.79}=0.117,
\end{gathered}
$$

or extinction occurs at a mole fraction of approximately $10.5 \%$ oxygen. The corresponding burning rate at extinction in this oxygen atmosphere can be found from Eq. (33) as follows:

Let $\mathrm{h}=14 \mathrm{~W} / \mathrm{m}^{2} \mathrm{~K}$ (a typical value corresponding to natural convection) and assume the blocking factor $=1$.

$$
\dot{m}_{\text {extinct }}^{\prime \prime}=\left\{\frac{h}{c_{g}}\left[Y_{\text {ox, }, \infty} \Delta H_{c} / r+c_{g}\left(T_{\infty}-T_{\nu}\right)\right]-\sigma T_{v}^{4}\right\} / L_{g}
$$


where now we include the re-radiation loss.

$$
m_{\text {extinct }}^{\prime \prime}=\left\{\left(\frac{14}{1}\right)\left[0.117(25.2) / 2+10^{-3}(293-650)\right\}-5.67 \times 10^{-11}(650)^{4}\right\} / 1.63
$$

or

$$
\dot{m}_{\text {extinct }}^{\prime \prime}=3.4 \mathrm{~g} / \mathrm{m}^{2} \mathrm{~s} \text {. }
$$

The heat transfer coefficient used above was selected as a plausible value that would lead to a typical value for $\mathrm{m}^{\text {" }}$ found at extinction. Thus, under the condition given above, the PMMA will extinguish in an oxygen environment of $10.5 \%$ with a maximum burn rate of $3.4 \mathrm{~g} / \mathrm{m}^{2} \mathrm{~s}$ just before extinction.

By considering all the terms in Eq. (38) we can determine a relationship among the "independent" parameters that must hold at extinction. For example, for fixed values of $T_{s}, Y_{a x, \infty}, T_{\infty}$, there is a critical value of $\mathscr{L}^{\prime}$ at extinction $\left(\mathrm{T}_{\mathrm{f}}=1600 \mathrm{~K}\right)$.

\section{Example 2. Quasi-steady suppression of PMMA}

As another example let us examine the steady burning of PMMA simultaneously exposed to an irradiance $\left(\dot{q}^{\prime \prime}\right.$ ext, $\left.r\right)$ and a steady water spray $\left(m_{w}\right)$. From Eqns. (22) and (36),

$$
\mathscr{Q}^{\prime}=L_{g}+\frac{\sigma T_{v}^{A}+\dot{m}_{w}^{\prime \prime} L_{w}-\dot{q}_{e x t, r}^{\prime \prime}}{\dot{m}^{\prime \prime}}
$$

Let $\mathrm{Y}_{a x \infty}=0.233, \mathrm{~T}_{\infty}=293 \mathrm{~K}$ and the previous PMMA properties. Substituting into Eq. (38) yields

$$
\begin{gathered}
10^{-3}(1600-650)=\frac{\left\{\left[25.2-\left(1.63+5.67 \times 10^{-11}(650)^{4}+\dot{m}_{w}^{\prime \prime}(2.6)-\dot{q}_{\text {ext, }}^{\prime \prime}\right]\right\}\right.}{\dot{m}_{\text {extinct }}} \\
\text { or } \dot{m}_{\text {extinct }}^{\prime \prime}=\frac{2.6 \dot{m}_{w}^{\prime \prime}+10.1-\dot{q}_{\text {ex, }, y}^{\prime \prime}}{13.2}
\end{gathered}
$$


From the steady PMMA (non-charring) mass loss Equation (21) with the water term included as in $^{\text {" }}$ w $\mathrm{L}_{\mathrm{w}}$ on the right side,

$$
\dot{m}^{\prime \prime} L_{g}=\left(\frac{h}{c_{g}}\right)\left[Y_{o x, \infty} \Delta H_{c}\left(1-X_{p}\right) / r+c_{g}\left(T_{-}-T_{v}\right]+\dot{q}_{f, r}^{\prime \prime}+\dot{q}_{e x, r}^{\prime \prime}-\sigma T_{v}^{4}-\dot{m}_{w}^{\prime \prime} L_{w}\right.
$$

where the blocking factor has been taken as one. Here we will take $h=8 \mathrm{~W} / \mathrm{m}^{2} \mathrm{~K}$ to match the data for no water application. Ignoring flame radiation loss, yields

$$
\begin{gathered}
\dot{m}^{\prime \prime}(1.63)=\left(\frac{8}{1}\right)\left[0.233(25.2) / 2+10^{-3}(293-650)\right]+\dot{q}_{\text {ext, }}^{\prime \prime}-10.1-2.6 \dot{m}_{w}^{\prime \prime} \\
\text { or } \dot{m}^{\prime \prime}=6.4+0.61 \dot{q}_{\text {ext, }}^{\prime \prime}-1.6 \dot{m}_{w}^{\prime \prime}\left(\frac{g}{m^{2}-s}\right)
\end{gathered}
$$

with $q_{\text {ext,r }}^{\prime \prime}$ in $\mathrm{kW} / \mathrm{m}^{2}$. Eq. (41) gives the burning rate under all conditions. Equating this to Eq. (40) gives the relationship holding at extinction:

$$
\begin{gathered}
0.20 \dot{m}_{w}^{\prime \prime}+0.77-0.076 \dot{q}_{e x, r}^{\prime \prime}=6.4+0.61 \dot{q}_{e x t, r}^{\prime \prime}-1.6 \dot{m}_{w}^{\prime \prime} \\
\text { or } \dot{q}_{e x t, r}^{\prime \prime}=2.6 \dot{m}_{w}^{\prime \prime}-8.2\left(\frac{\mathrm{kW}}{\mathrm{m}^{2}}\right)
\end{gathered}
$$

Eq. (42) gives the critical irradiance for a given water spray rate at extinction. The results of Eq. (41) and (42) are in qualitative agreement with the experimental data of Magee and Reitz [8] as shown in Figure 9 with the critical irradiance at extinction underestimated by the theory. Nevertheless, these results show the versatility and level of accuracy of the simple burning rate model presented.

\section{Conclusions}

A simple burning rate model has been developed for a solid which is based on a stagnant film diffusion flame and a control volume formulation for the solid. External irradiance, charring and other transient effects, back-face heat loss and water application are phenomena included. The model is shown to yield results that could have acceptable accuracy for making estimates of burning rate for materials. It is shown that the steady-state heat of gasification could be estimated from smallscale test data by examining the slope of the peak burning rate versus irradiance for both charring 
and non-charring materials. The terms in the model qualitatively describe the burning rate seen in test data for both charring and non-charring materials. An extinction model based on a critical flame temperature yields results which are qualitatively correct with accuracy that may be sufficient to predict first-order effects. 


\section{References}

1. Tewarson, A, "Generation of Heat and Chemical Compounds in Fires," The SFPE Handbook of Fire Protection Engineering, P. DiNenno, ed., Nat. Fire Prot. Assoc.,S.F.P.E., Boston, MA, 1988.

2. Jackson, J.L., "Direct Measurement of Heat of Gasification for Polymethylmethacrylate," NISTIR 88-3809, Natl. Inst. Stand. and Technology, September 1986.

3. Walton, W. D. and Twilley, W. H., "Heat Release and Mass Loss Rate Measurements for Selected Materials," NBSIR 84-2960, Nat. Bur. Stand., December 1984.

4. Kulkarni, A. K., "Upward Flame Spread on Vertical Walls," NIST-GCR-89-565, Natl. Inst. Stand. and Technology, April 1989.

5. Tsantaridis, L. and Ostman, B., "Smoke, Gas and Heat Release Data for Building Products in the Cone Calorimeter," Trateknik Centrum, Report I 8903013, Sweden, 1989.

6. Williams, F.A., "A Review of Flame Extinction", Fire Safety Journal, Vol. 3, 1981.

7. Kanury, AM., Introduction to Combustion Phenomena, Gordon and Breach, Sci. Pub. Inc., New York, 1975.

8. Magee, R.S. and Reitz, R.D., "Extinguishment of Radiation Augmented Plastic Fires by Water Sprays," FMRC Tech. Rept. 22357-1, Factory Mutual Research Corp., Norwood, MA, March 1974. 


\section{Nomenclature}

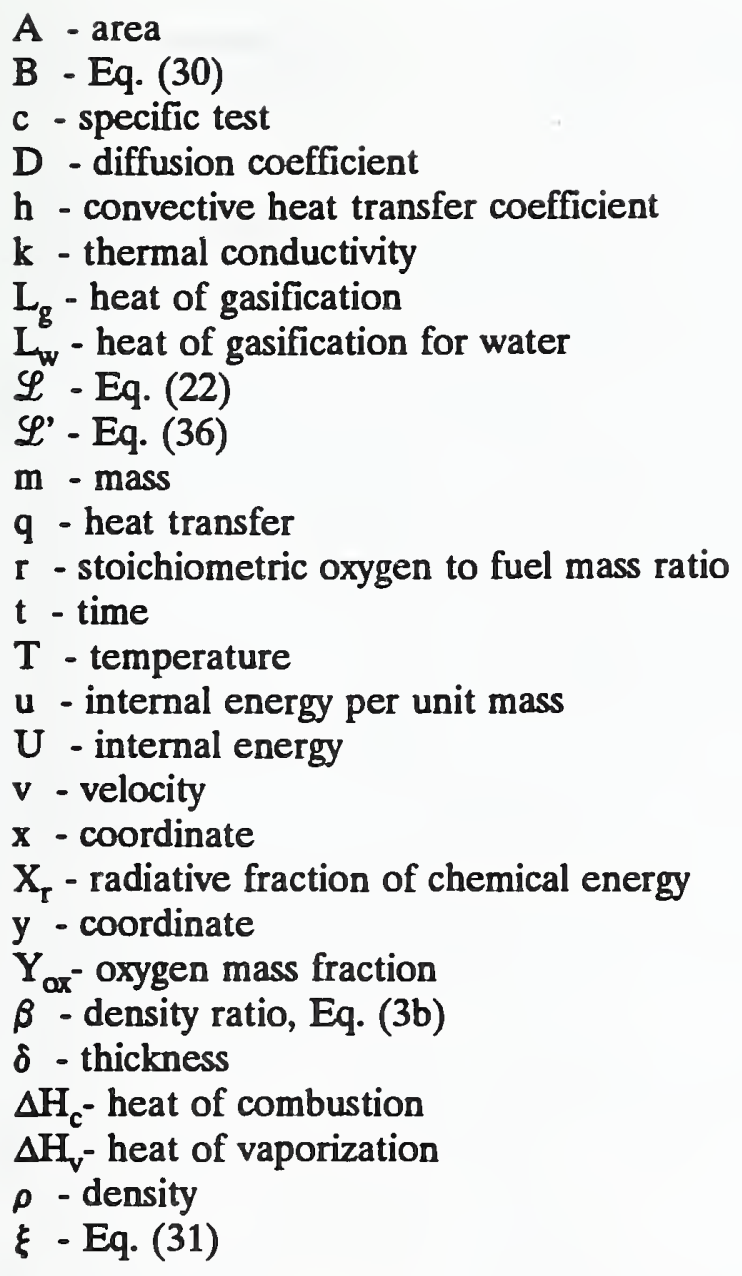

\section{Subscripts}

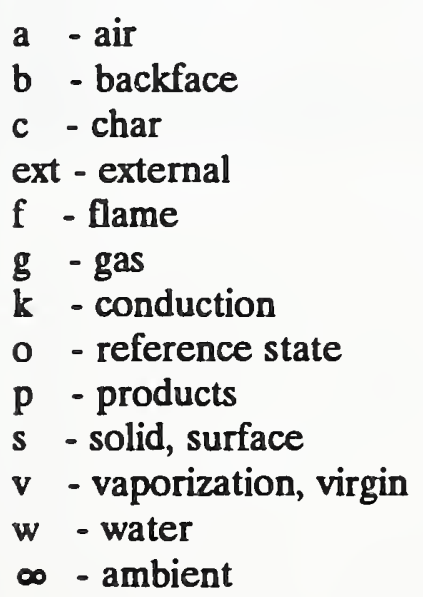




\section{Superscripts}
() - per unit time
( ) $n$ - per unit area
( )" - per unit volume 
Table 1

Heat of Gasification Values at Peak Burning Conditions

\begin{tabular}{|c|c|c|}
\hline Material & $\underset{(\mathrm{kJ} / \mathrm{g})}{\mathrm{L}}$ & Data Source \\
\hline PMMA & 1.89 & Jackson [2] \\
\hline PMMA & 1.63 & Tewarson [1] \\
\hline Oak & 4.0 & Jackson [2] \\
\hline Particle Board & 5.4 & {$[3],[4],[5]$} \\
\hline Insulating Fiber Board & 4.0 & Ostman [5] \\
\hline $\begin{array}{l}\text { Medium Density Fiber } \\
\text { Board }\end{array}$ & 4.8 & $n \quad n$ \\
\hline Spruce panel & 6.3 & $n \quad n$ \\
\hline $\begin{array}{l}\text { Melamine-faced Particle } \\
\text { Board }\end{array}$ & 4.8 & $n \quad n$ \\
\hline $\begin{array}{l}\text { Paper Wallcovering on } \\
\text { Gypsum Board }\end{array}$ & 1.5 & $n n$ \\
\hline $\begin{array}{l}\text { Plastic Wallcovering on } \\
\text { Gypsum Board }\end{array}$ & 3.7 & $n \quad n$ \\
\hline $\begin{array}{l}\text { Paper Wallcovering on } \\
\text { Particle Board }\end{array}$ & 6.5 & $n \quad n$ \\
\hline $\begin{array}{l}\text { Textile Wallcovering on } \\
\text { Gypsum Board }\end{array}$ & 1.5 & " " \\
\hline $\begin{array}{l}\text { Textile Wallcovering on } \\
\text { Rockwool }\end{array}$ & 2.8 & $n " n$ \\
\hline Rigid Polyurethane Foam & 3.1 & $" n$ \\
\hline
\end{tabular}


curouthusurush - Flame

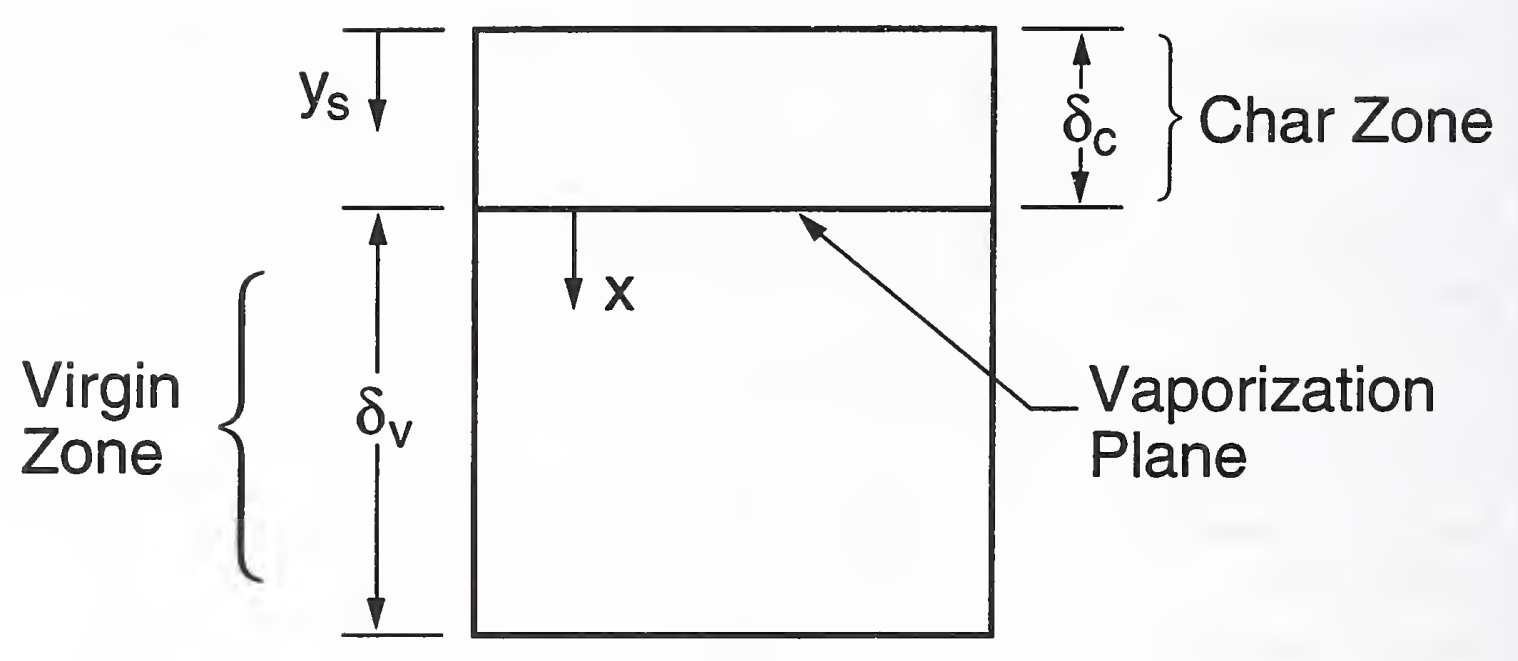

Figure 1. Solid decomposition model 


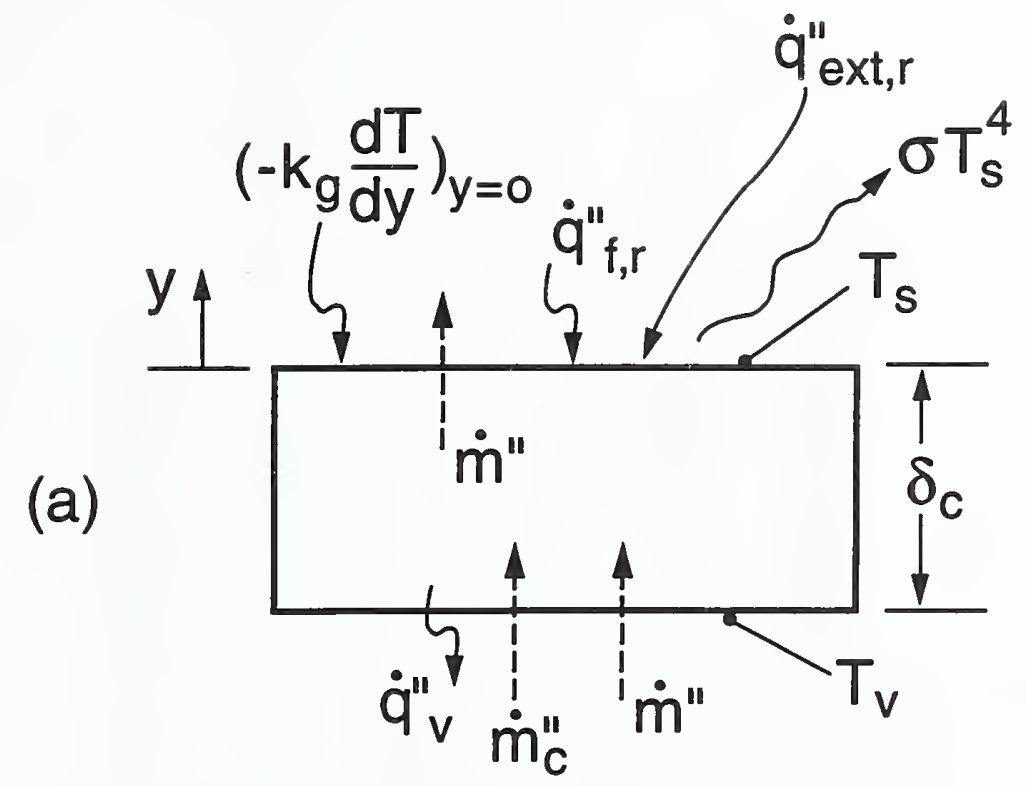

Figure 2a. Char layer process

(b)

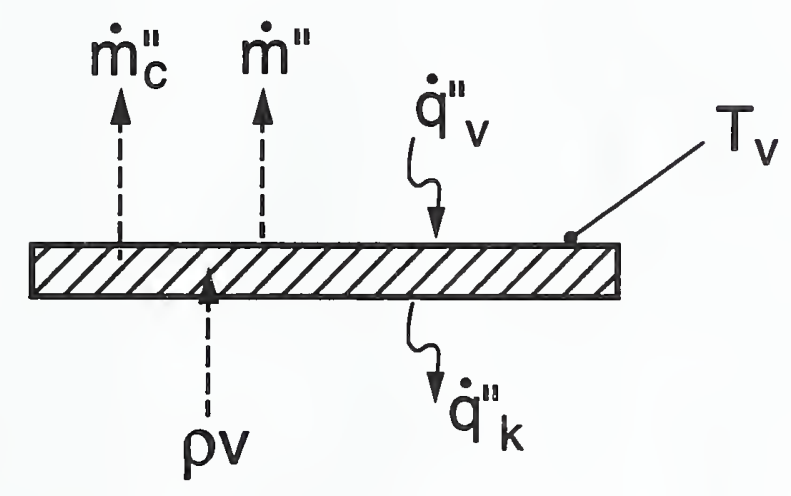

Figure 2b. Vaporization process

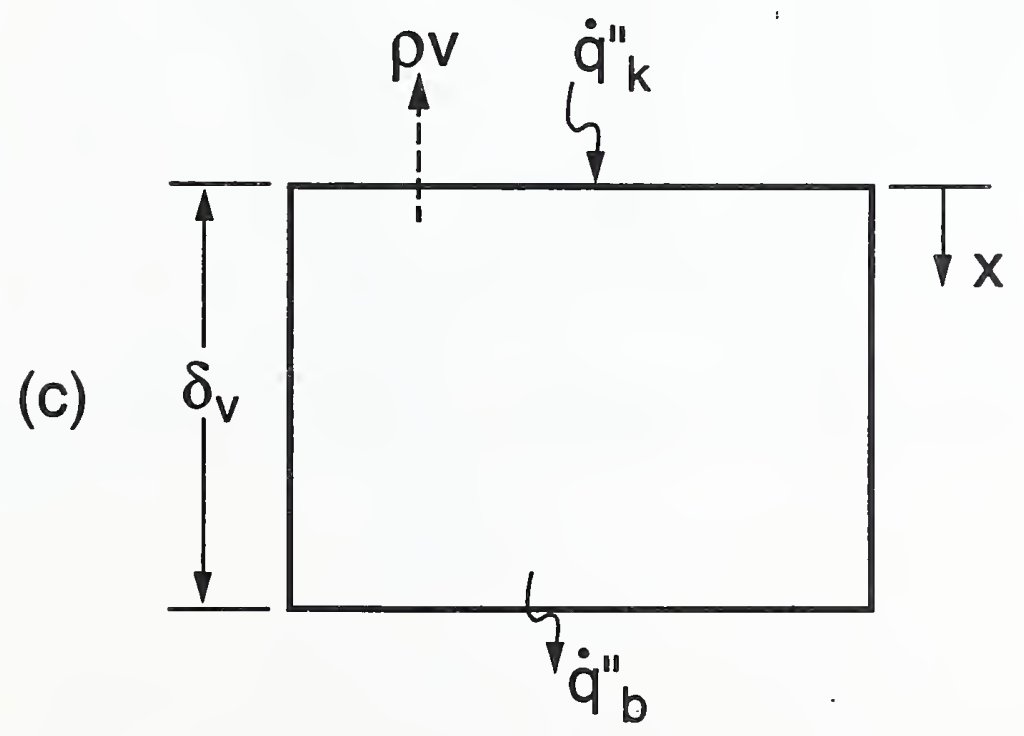

Figure 2c. Virgin material heat transfer processes 


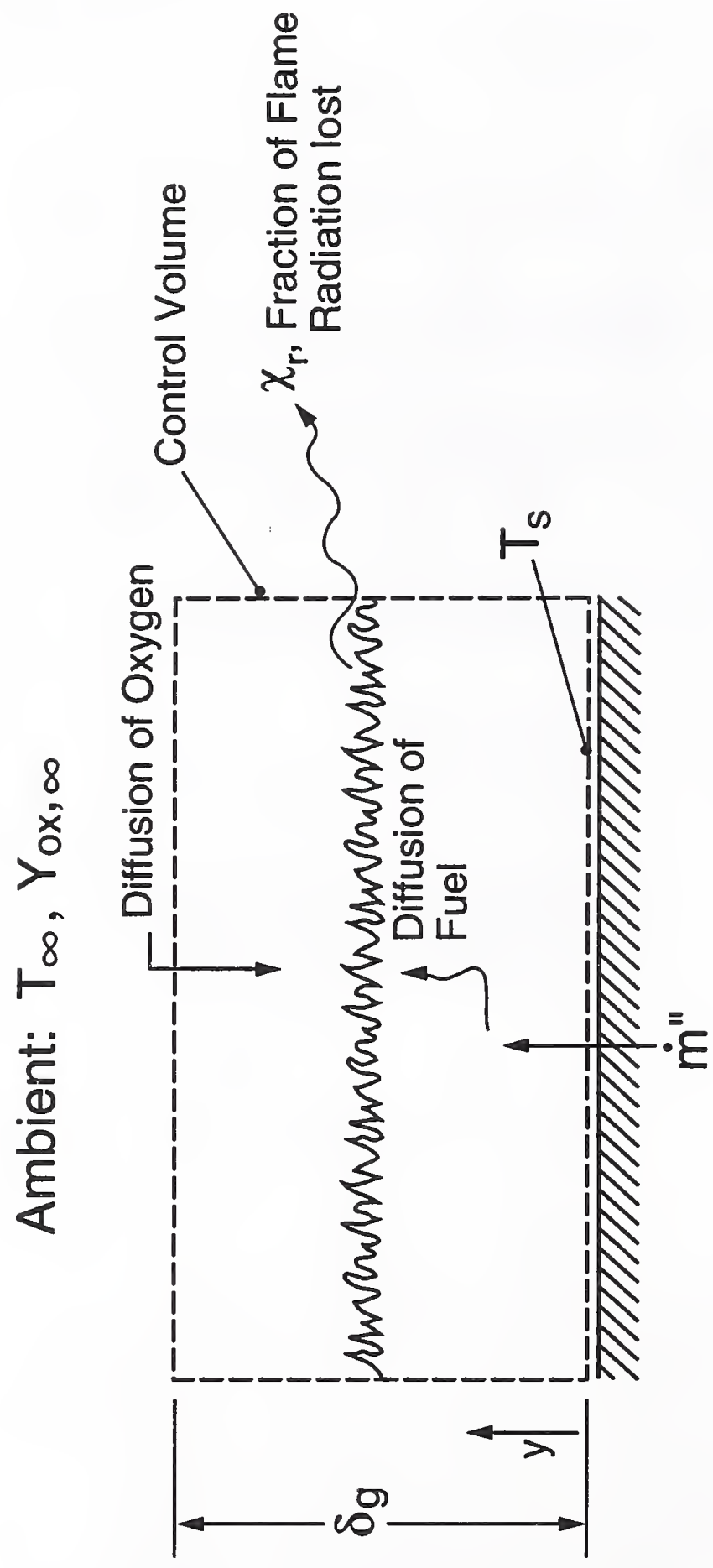

ह్ 


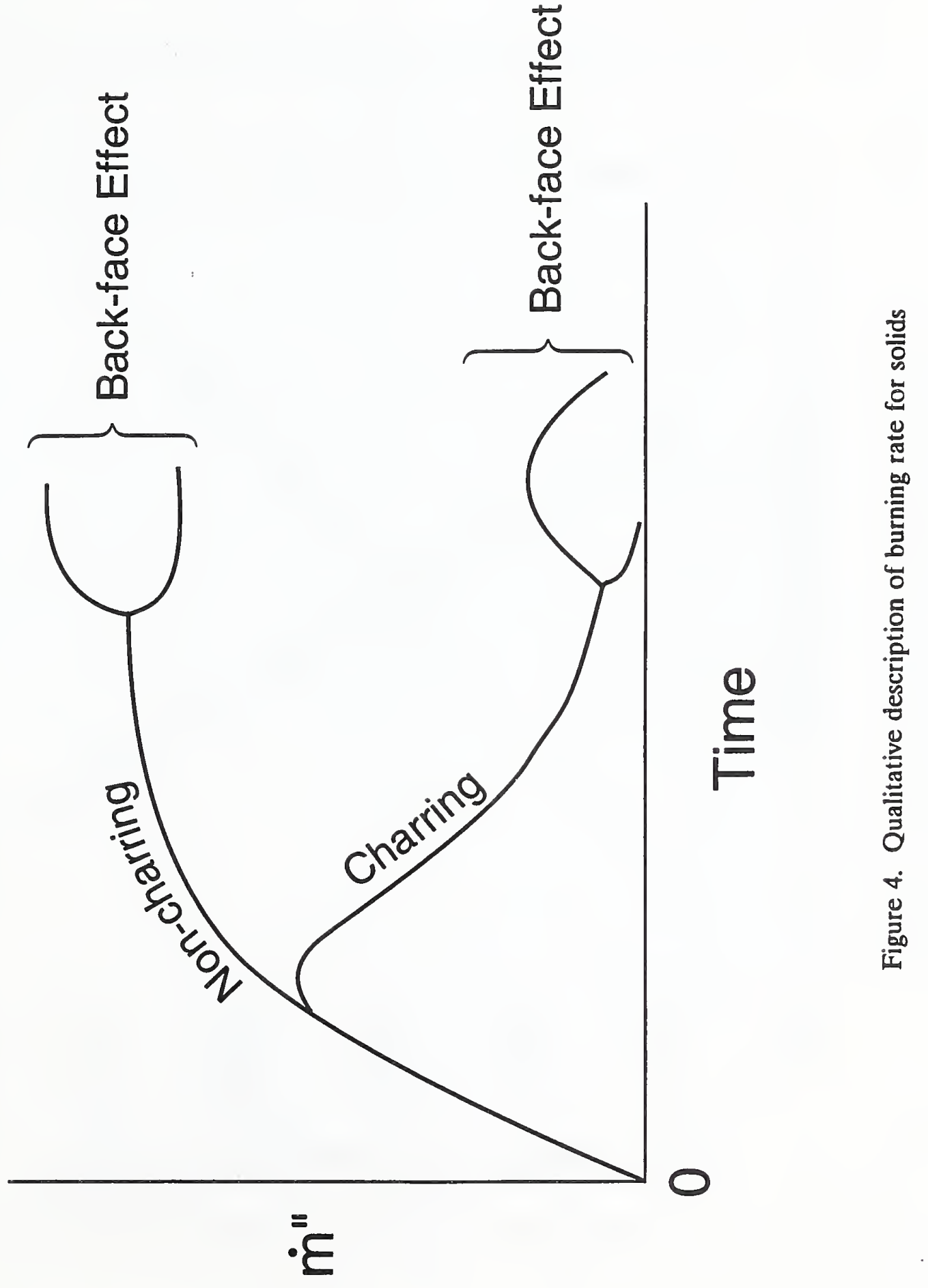




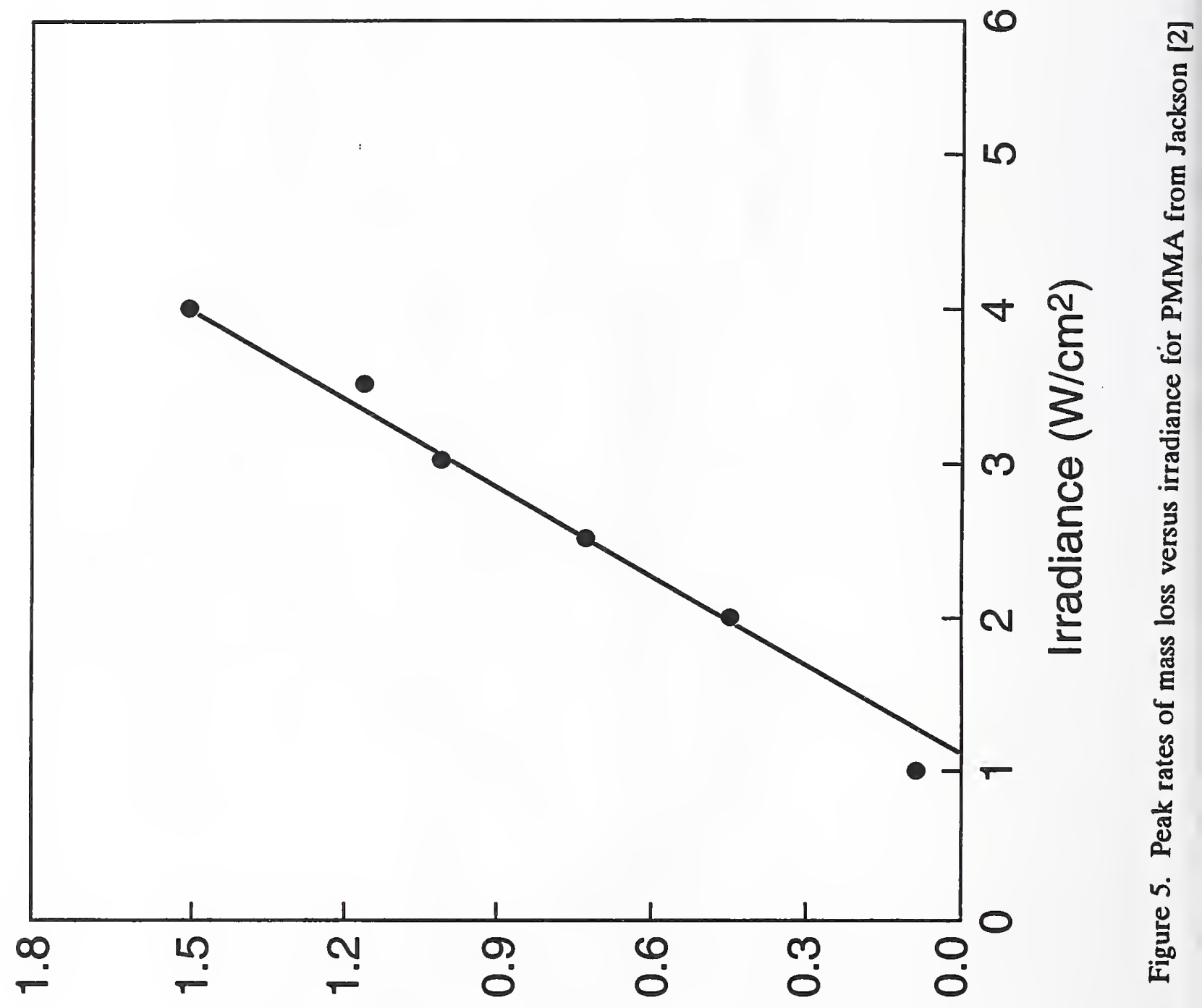

(szmo/6m) ssoך ssew to әృеч yеәd 


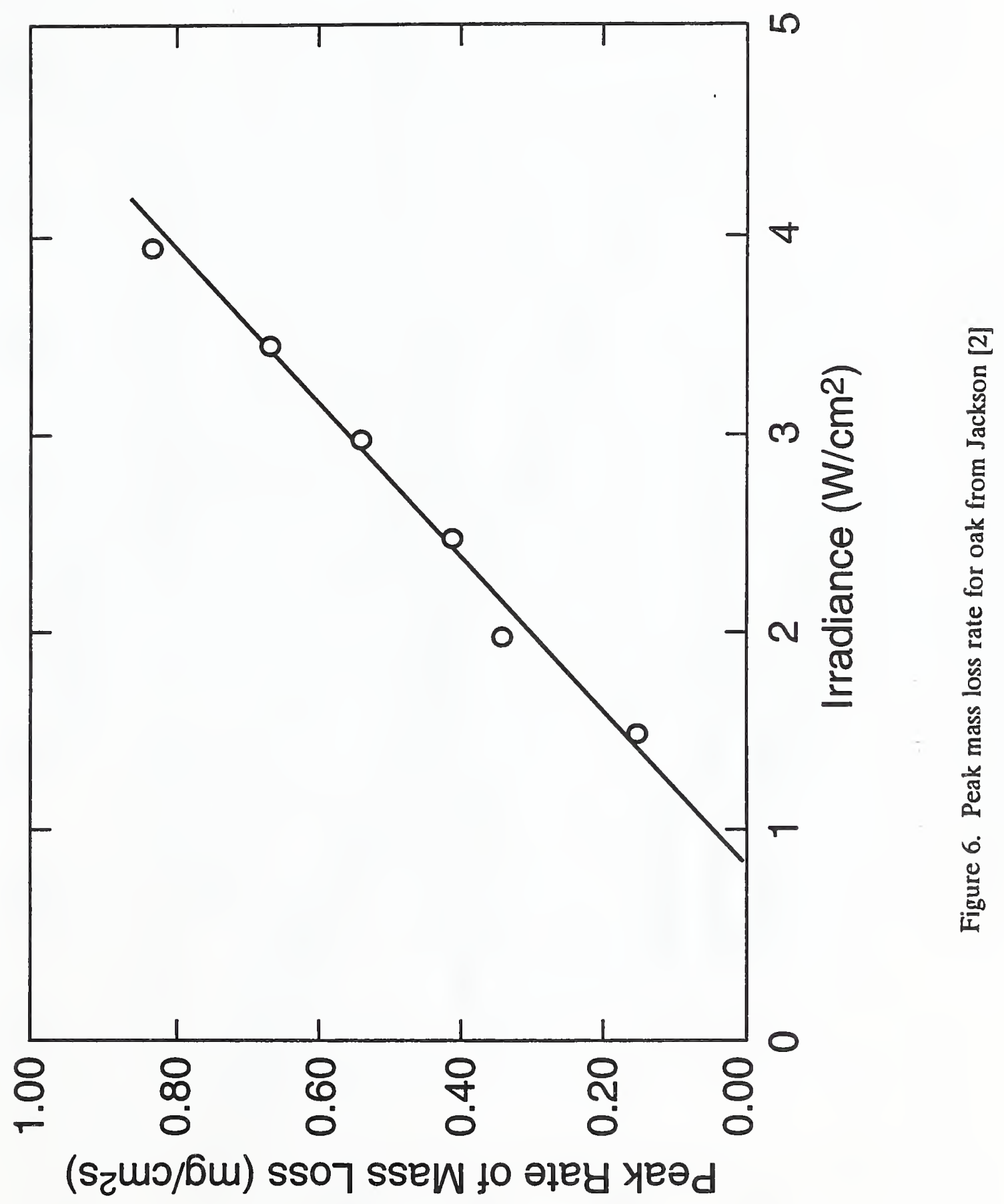




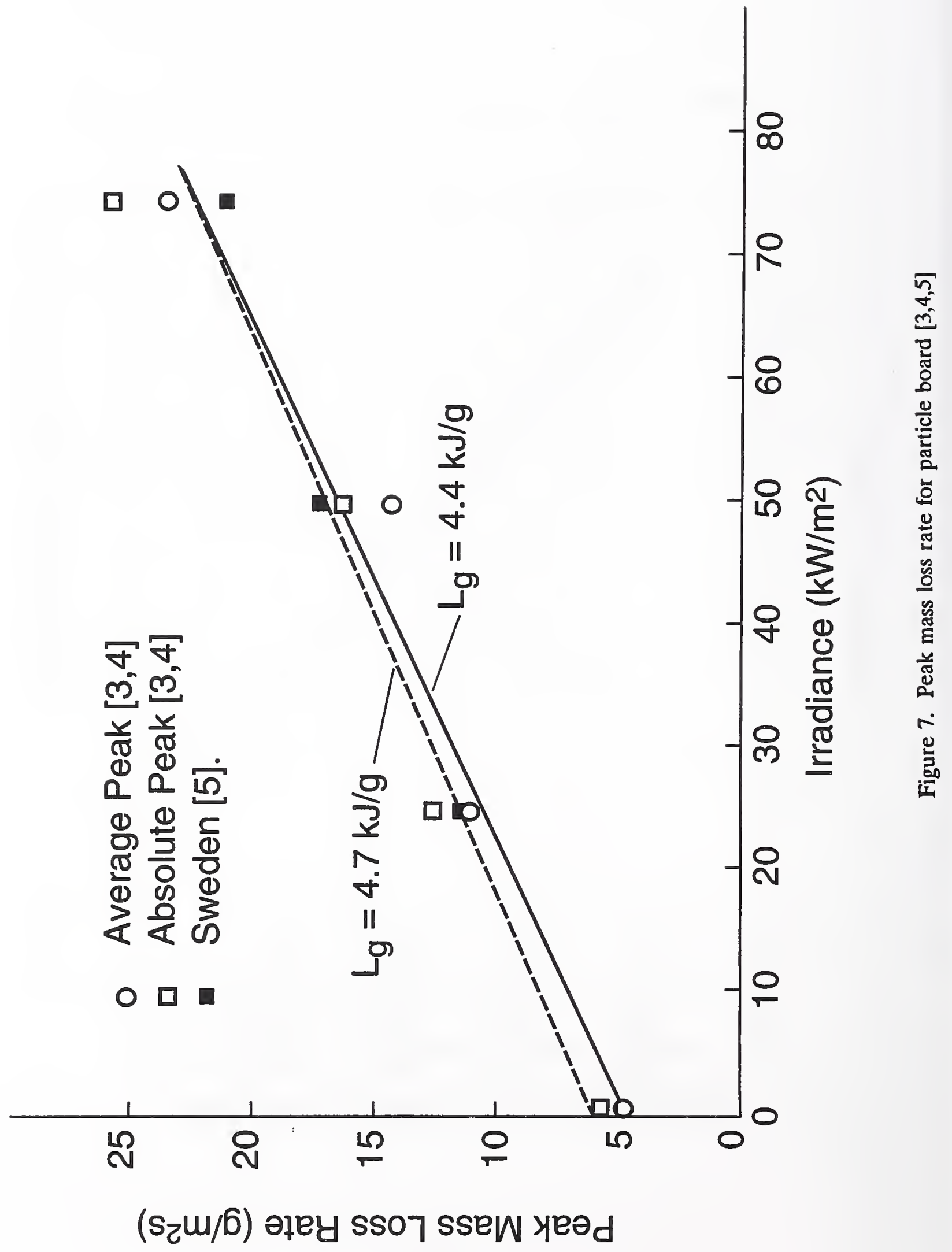




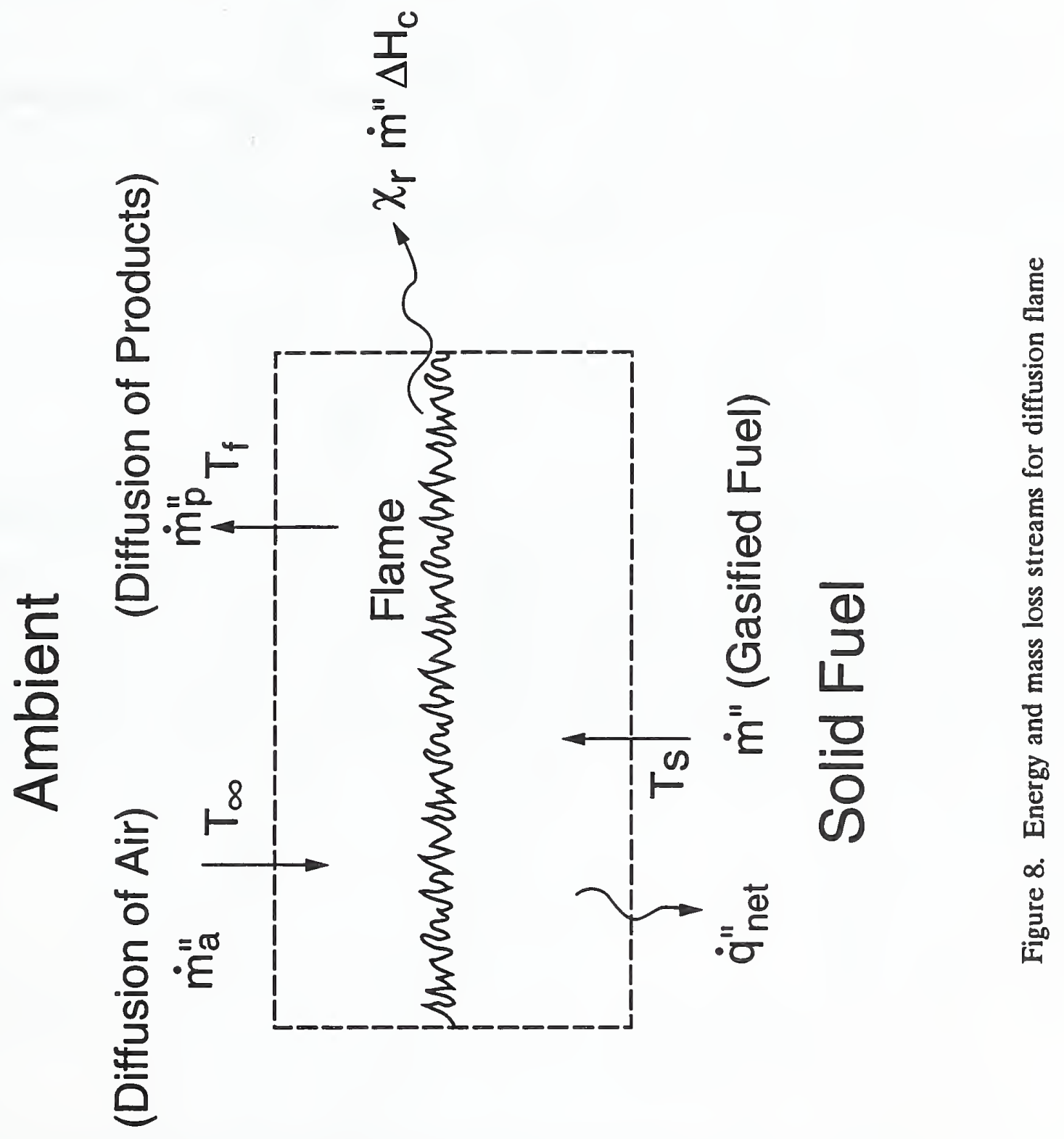




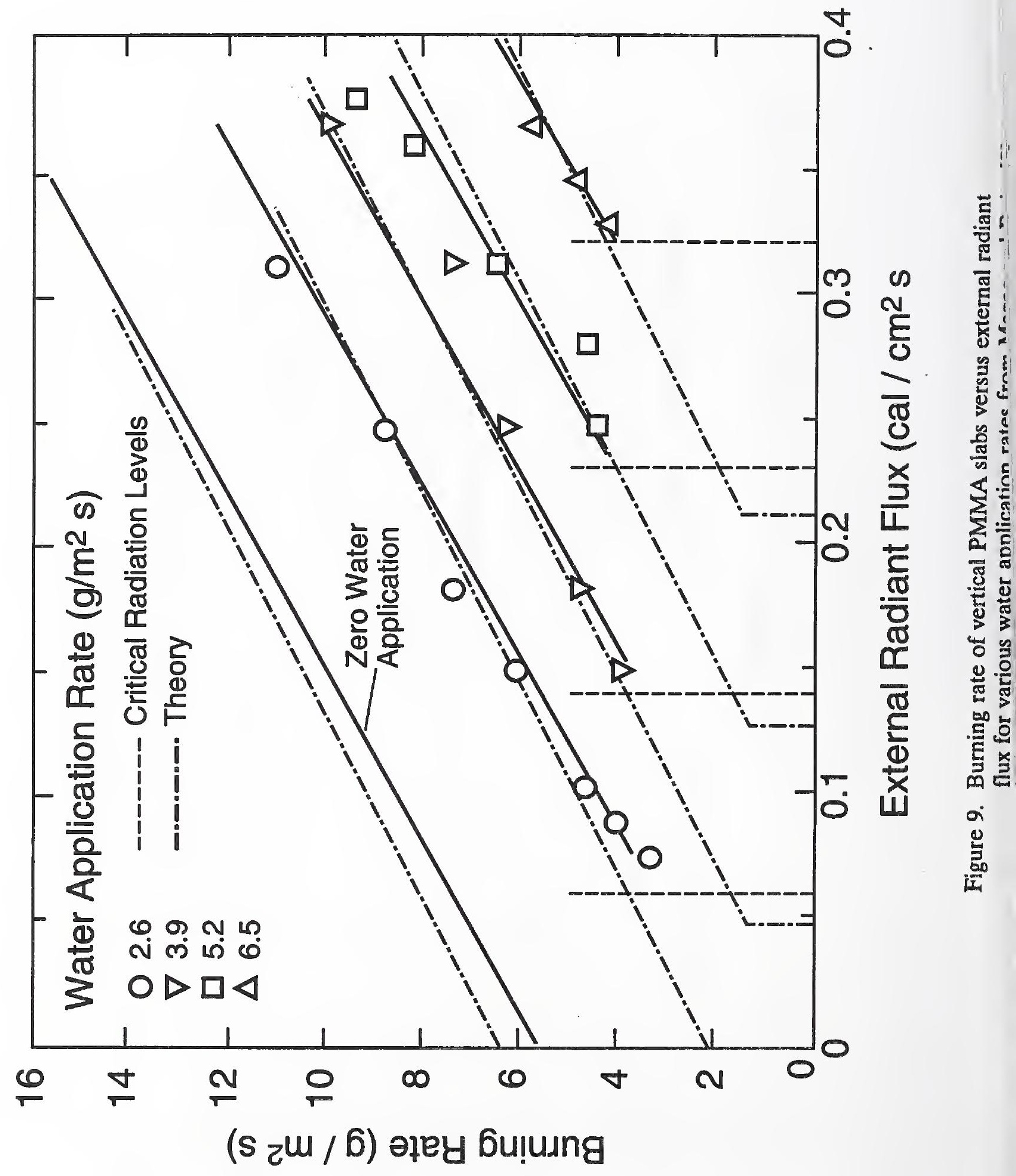




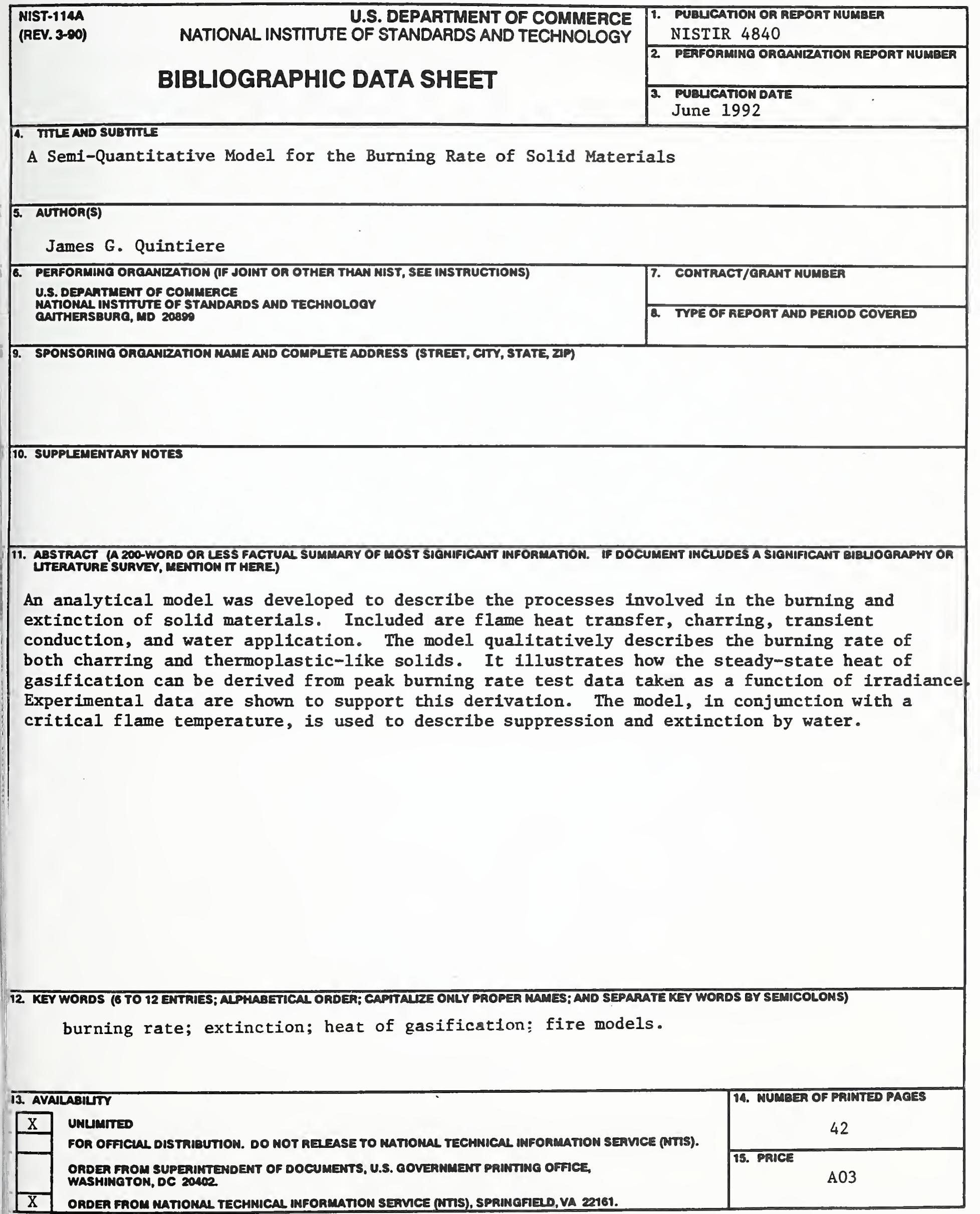




